\title{
Sodium dichloroacetate exhibits anti-leukemic activity in B-chronic Iymphocytic leukemia (B-CLL) and synergizes with the p53 activator Nutlin-3
}

\author{
Chiara Agnoletto ${ }^{1, *}$, Elisabetta Melloni ${ }^{1, *}$, Fabio Casciano ${ }^{1}$, Gian Matteo Rigolin ${ }^{2}$ \\ Erika Rimondi ${ }^{3}$, Claudio Celeghini ${ }^{3}$, Laura Brunelli ${ }^{1}$, Antonio Cuneo ${ }^{2}$, Paola \\ Secchiero $^{1}$, Giorgio Zauli ${ }^{4}$ \\ ${ }^{1}$ Department of Morphology, Surgery and Experimental Medicine and LTTA Centre, University of Ferrara, Ferrara, Italy \\ ${ }^{2}$ Department of Medical Sciences, University of Ferrara-Arcispedale S.Anna, Ferrara, Italy \\ 3 Department of Life Sciences, University of Trieste, Trieste, Italy \\ ${ }^{4}$ Institute for Maternal and Child Health, IRCCS "Burlo Garofolo", Trieste, Italy \\ * These two authors equally contributed to this work \\ Correspondence to: Paola Secchiero, email: paola.secchiero@unife.it \\ Keywords: Sodium dichloroacetate, Nutlin-3, B-CLL, p21 \\ Received: March 21, $2014 \quad$ Accepted: May 26, $2014 \quad$ Published: May 26, 2014
}

This is an open-access article distributed under the terms of the Creative Commons Attribution License, which permits unrestricted use, distribution, and reproduction in any medium, provided the original author and source are credited.

\section{ABSTRACT}

The anti-leukemic activity of the mitochondria-targeting small molecule sodium dichloroacetate (DCA), used alone and in association with the small molecule inhibitor of the p53/MDM2 interaction Nutlin-3, was analyzed in primary B-chronic lymphocytic leukemia $(B-C L L)$ samples $(n=22)$, normal peripheral blood cells $(n=10)$ and in $p 53^{\text {wild- }}$ type EHEB, JVM-2, JVM-3 B lymphoblastoid cell lines. DCA exhibited a dose-dependent anti-leukemic activity in both primary B-CLL and B leukemic cell lines with a functional p53 status and showed a synergistic cytotoxic activity when used in combination with Nutlin-3. At the molecular level, DCA positively regulated p53 activity, as documented by post-transcriptional modifications of p53 protein, and synergized with Nutlin-3 in increasing the expression of the p53-target genes MDM2, PUMA, TIGAR and in particular p21. The potential role of p21 in mediating the DCA+Nutlin-3 anti-leukemic activity was underscored in knocking-down experiments. Indeed, transfection of leukemic cells with p21 siRNAs significantly decreased the DCA+Nutlin-3-induced cytotoxicity. Taken together, our data emphasize that DCA is a molecule that merits to be further evaluated as a chemotherapeutic agent for B-CLL, likely in combination with other therapeutic compounds.

\section{INTRODUCTION}

Most cancers possess a near-universal metabolic phenotype known as the 'Warburg effect', which is characterized by enhanced glycolytic flux for ATP production, glucose to lactate conversion and reduced mitochondrial oxidative phosphorylation, even under aerobic conditions [1-3]. There is now growing evidence that the mitochondria might be primary targets in cancer therapeutics instead of simple bystanders during cancer development. Interestingly, this cancer-specific metabolic remodeling can be reversed by dichloroacetate (DCA), a mitochondria-targeting small molecule able to penetrate most tissues after oral administration [4]. DCA shows several interesting characteristics, such as effectiveness in a variety of solid tumor cell lines and relatively low toxicity on normal cells. Moreover, DCA is a generic drug with low price, which has been in use in humans for more than 30 years. Most of the current studies on DCA have been performed on solid tumors, such as non-small cell lung cancer, breast cancer and most glioblastoma cell lines [4,5]. Additional studies have been performed on endometrial, prostate, breast and colorectal [6-14] cancer cells and more recently on multiple myeloma cells [15]. On the other hand, since leukemic cell lines use glycolysis but also non-glucose bioenergetic pathways such as fatty 
Table 1: Clinical and laboratory features of the B-CLL patients involved in this study

\begin{tabular}{|c|c|c|c|c|c|c|c|c|c|}
\hline $\begin{array}{l}\text { Patient } \\
\#\end{array}$ & Age/Sex & $\begin{array}{l}\text { Rai } \\
\text { stage }\end{array}$ & $\begin{array}{l}\text { WBC count } \\
\left(\mathrm{x} 10^{3} / \mathrm{mL}\right)\end{array}$ & $\begin{array}{l}\% \mathrm{CD} 38+ \\
\text { cells }\end{array}$ & ZAP-70 & IgVH status & $\begin{array}{l}\text { Cytogenetic } \\
\text { abnormalities } \\
\text { (FISH) }\end{array}$ & p53 status & Therapy \\
\hline 1 & 77/M & 0 & 81.4 & 2 & 2 & mut & del13q omoz. & WT & none \\
\hline 2 & $85 / F$ & 1 & 54 & 1 & 5 & mut & $\operatorname{tri12}$ & WT & Chl \\
\hline 3 & $68 / \mathrm{M}$ & 0 & 82.9 & 3.3 & 21 & mut & del13q & na & none \\
\hline 4 & $79 / \mathrm{F}$ & 1 & 47.9 & 2.9 & na & na & na & na & FCR \\
\hline 5 & $75 / \mathrm{F}$ & 1 & 56.6 & 1.9 & 8 & mut & na & na & none \\
\hline 6 & $73 / \mathrm{F}$ & 1 & 95 & 2.1 & 50 & mut & del13q & WT & Chl \\
\hline 7 & $75 / \mathrm{M}$ & 0 & 96.8 & 1.1 & 30 & mut & del13q & WT & none \\
\hline 8 & $79 / \mathrm{F}$ & 0 & 54.8 & 6.3 & 1.8 & unmut & $\begin{array}{l}\text { del11q/del13q } \\
\text { omoz. }\end{array}$ & WT & $\mathrm{F}$ \\
\hline 9 & $66 / \mathrm{M}$ & 0 & 108.1 & 0 & 24.3 & unmut & del13q & WT & FCR \\
\hline 10 & $56 / \mathrm{M}$ & II & 128.3 & 1.2 & 60 & unmut & Normal & WT & FCR \\
\hline 11 & $82 / \mathrm{F}$ & 0 & 23.3 & 50.9 & 6.4 & mut & Normal & WT & none \\
\hline 12 & $55 / \mathrm{F}$ & 0 & 9.3 & 77.9 & 13 & unmut & del11q & WT & none \\
\hline 13 & $65 / \mathrm{M}$ & 0 & 25.3 & 6 & 27.1 & mut & Normal & WT & none \\
\hline 14 & $75 / \mathrm{M}$ & 0 & 23.1 & 21 & 19.7 & unmut & del13q & WT & none \\
\hline 15 & 73/M & 0 & 27.7 & 10.3 & 10.2 & mut & del13q & WT & none \\
\hline 16 & $71 / \mathrm{F}$ & 0 & 14.2 & 0 & 20.6 & na & del13q & WT & none \\
\hline 17 & $75 / \mathrm{M}$ & 0 & 59.7 & 6.8 & 0.3 & mut & del13q & WT & none \\
\hline 18 & $55 / \mathrm{F}$ & 0 & 86.5 & 7 & 7.4 & unmut & del13q & WT & none \\
\hline 19 & $77 / \mathrm{M}$ & IV & 100 & 15.4 & 72.1 & unmut & tris 12 & WT & Chl \\
\hline 20 & $51 / \mathrm{F}$ & 0 & 105 & 2.8 & 20 & unmut & del11q/del13q & WT & none \\
\hline 21 & $87 / F$ & II & 121 & 58.5 & 2.4 & unmut & del13q/tris 12 & WT & Chl \\
\hline 22 & $72 / \mathrm{M}$ & II & 21.2 & 55.2 & na & unmut & del13q/tris 12 & WT & none \\
\hline
\end{tabular}

FCR, fludarabine, cyclophosphamide, rituximab; Chl, chlorambucil; mut, mutated; unmut, unmutated; WT, wild-type; na, not available.

acid oxidation and/or amino-acid metabolism [16], the potential efficacy of DCA on leukemic cells should be investigated, also considering that no data are currently available on this issue.

On these bases, the aim of the present study was to evaluate the potential therapeutic perspectives of DCA as anti-leukemic drug. For this purpose, DCA was added to primary B chronic lymphocytic leukemia (B-CLL) cells and to primary normal peripheral blood mononuclear cells (PBMC), either alone or in association with Nutlin-3, a small molecule inhibitor of the MDM2/p53 interaction. In addition, the molecular mechanisms of action of DCA+Nutlin-3 were evaluated in a panel of $\mathrm{p} 53^{\text {wild-type }} \mathrm{B}$ leukemic cell lines (EHEB, JVM-2, JVM-3).

\section{RESULTS}

\section{DCA promotes cytotoxicity in primary B-CLL patient derived cells, but not in normal peripheral blood cells}

In the first group of experiments, the effect of DCA was comparatively analyzed on primary PBMC derived from B-CLL patients $(\mathrm{n}=22$; Table 1$)$ and from healthy blood donors $(\mathrm{n}=10)$. Treatment with DCA, used in the range of 1-30 $\mathrm{mM}$ for up to 48 hours, exhibited a doseand time-dependent cytotoxicity, resulting in significant reduction of leukemic cell viability with respect to the untreated cultures, at concentrations $\geq 3 \mathrm{mM}$ in B-CLL patient cell samples (Figure 1A). The $\mathrm{IC}_{50}$ mean values $( \pm \mathrm{SD})$ of cytotoxicity of DCA in B-CLL patient samples 
were $24 \pm 15 \mathrm{mM}$ and $12 \pm 12 \mathrm{mM}$ at 24 and 48 hours of treatment, respectively (Figure 1B). On the other hand, PBMC obtained from healthy donors were significantly less susceptible to DCA cytotoxicity as compared to primary B-CLL cells, with $\mathrm{IC}_{50}$ mean values $( \pm \mathrm{SD})$ of cytotoxicity of $198 \pm 106 \mathrm{mM}$ and $93 \pm 52 \mathrm{mM}$ at 24 and 48 hours of treatment (Figure 1A-B), clearly showing that normal PBMC were completely resistant to DCA effects at concentrations $\leq 10 \mathrm{mM}$. Thus, in line with previous data obtained in solid tumor cell models [4-14] and multiple myeloma [15], we have demonstrated for the first time that DCA promoted a significant cytotoxicity also in primary B-CLL samples but not in normal PBMC.

\section{DCA activates the p53 pathway in p53 ${ }^{\text {wild-type }} B$ leukemic cell lines}

Since most B-CLL at diagnosis are p53 $3^{\text {wild-type }}$ $[17,18]$, a condition also characterizing the primary B-CLL samples analyzed in this study, it is noteworthy that previous studies on solid tumors have implicated the p53 pathway in mediating the anti-tumoral activity of DCA $[5,6,19]$. Therefore, in order to investigate the potential involvement of p53 in mediating the anti-leukemic activity of DCA, we next performed a series of experiments on three p53 ${ }^{\text {wild-type }} \mathrm{B}$ leukemic cell lines (EHEB, JVM-2 and JVM-3), used as model systems. As shown in Figure $2 \mathrm{~A}$, treatment with DCA resulted in a dose-dependent reduction of cell viability in all the $\mathrm{p} 53^{\text {wild-type }} \mathrm{B}$ leukemic cell lines tested, with $\mathrm{IC}_{50}$ values ranging from 25 to 30.4 $\mathrm{mM}$ at 24 hours of treatment and from 15.2 to $18.6 \mathrm{mM}$ at 48 hours of treatment, comparable to those of primary B-CLL cells (Figure 1B). Flow cytometric analysis of these leukemic cell cultures demonstrated that treatment with DCA induced early accumulation in G1 phase of the cell cycle (Figure 2B) and promoted apoptosis in all leukemic cell lines (Figure 2C). The cytotoxic effects of DCA on the B cell lines were coupled to the ability of DCA to reduce the glucose consumption (data not shown) and the mitochondrial membrane potential (Figure 2D).

Based on these evidences, documenting the antiproliferative/pro-apoptotic activity of DCA in B leukemic cells, we next assessed the effect of DCA treatment on the expression of p53 in the EHEB, JVM-2, JVM-3 cell lines by two-dimensional electrophoresis and immunoblotting, which allows separation of proteins based on their molecular weight (MW) and isoelectric point (pI). As shown in Figure 3A, two-dimensional electrophoresis revealed the presence of the full-length p53 $(\sim 53 \mathrm{kDa}, \mathrm{pI}$ $6-7.3)$ beside a group of spots below the $53 \mathrm{kDa}(\sim 40 \mathrm{kDa}$, pI 5.5-6.5) in the untreated cultures. Upon DCA treatment for 24 hours, it was possible to observe a slight increase in the full-length p53 protein in the EHEB cell line and, of note, the appearance of a series of isoforms above the $53 \mathrm{kDa}$ in all the cell lines, suggestive of p53 posttranslational modifications. In this respect, in Western blot assay we have documented that DCA dose-dependently

\section{A}
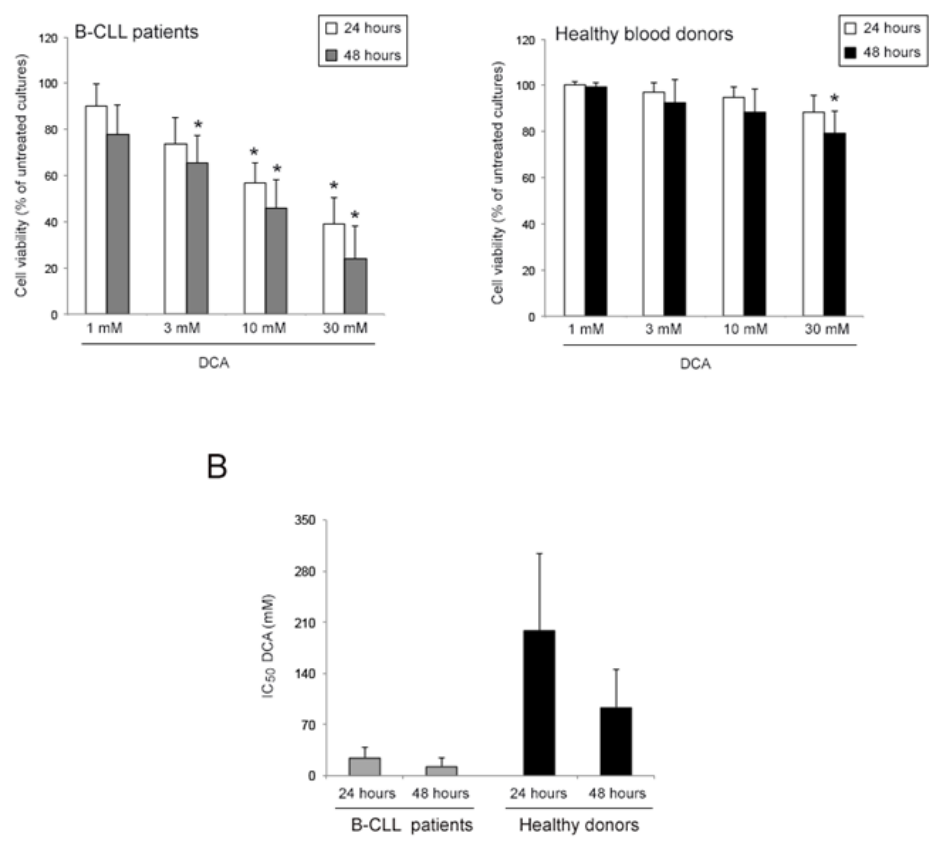

Figure 1: Comparative evaluation of cell viability in response to DCA in B-CLL patient leukemic cells and PBMC from healthy human blood donors. B-CLL patient cell samples $(n=22)$ and PBMC from healthy blood donors $(n=10)$ were exposed to serial doses of DCA (range 1-30 mM) as indicated. In A, cell viability was analyzed at 24 and 48 hours of treatment and was calculated as percentage of untreated cultures set to $100 \%$. Data are reported as mean values \pm SD. The asterisk indicates $p<0.05$ with respect to the untreated cultures. $\mathrm{In} \mathrm{B}, \mathrm{IC}_{50}$ values are reported as mean value $\pm \mathrm{SD}$. 
Table 2: Combination index values for the effect of DCA plus Nutlin-3 on viability of B-CLL patient cells and p53wild-type B cell lines

\begin{tabular}{|c|c|c|c|c|}
\hline Cells & ED50 & ED75 & ED90 & Average CI \\
\hline Patient \#1 & 0.33 & 0.29 & 0.26 & 0.29 \\
\hline Patient \#2 & 0.18 & 0.03 & 0.01 & 0.07 \\
\hline Patient \#3 & 0.37 & 0.38 & 0.4 & 0.38 \\
\hline Patient \#4 & 0.31 & 0.39 & 0.52 & 0.41 \\
\hline Patient \#5 & 0.43 & 0.37 & 0.34 & 0.38 \\
\hline Patient \#6 & 0.37 & 0.31 & 0.30 & 0.33 \\
\hline Patient \#7 & 0.37 & 0.32 & 0.29 & 0.33 \\
\hline Patient \#8 & 0.06 & 0.16 & 0.46 & 0.23 \\
\hline Patient \#9 & 0.2 & 0.56 & 1.91 & 0.79 \\
\hline Patient \#10 & 0.67 & 0.95 & 1.36 & 0.99 \\
\hline Patient \#11 & 0.20 & 0.27 & 0.37 & 0.28 \\
\hline Patient \#12 & 0.15 & 0.29 & 0.68 & 0.37 \\
\hline Patient \#13 & 0.05 & 0.06 & 0.09 & 0.07 \\
\hline Patient \#14 & 0.19 & 0.02 & 0.004 & 0.07 \\
\hline Patient \#15 & 0.35 & 0.1 & 0.03 & 0.16 \\
\hline Patient \#16 & 0.24 & 0.04 & 0.007 & 0.10 \\
\hline Patient \#17 & 0.11 & 0.30 & 0.80 & 0.40 \\
\hline Patient \#18 & 0.45 & 0.43 & 0.42 & 0.43 \\
\hline Patient \#19 & 0.01 & 0.08 & 0.58 & 0.22 \\
\hline Patient \#20 & 0.02 & 0.10 & 0.67 & 0.26 \\
\hline Patient \#21 & 0.22 & 0.24 & 0.29 & 0.25 \\
\hline Patient \#22 & 0.19 & 0.13 & 0.09 & 0.14 \\
\hline EHEB & 0.39 & 0.49 & 0.66 & 0.51 \\
\hline JVM-2 & 0.16 & 0.11 & 0.13 & 0.13 \\
\hline JVM-3 & 0.06 & 0.08 & 0.11 & 0.08 \\
\hline
\end{tabular}

ED indicates effect dose. The average combination index $(\mathrm{CI})$ values were calculated from ED50, ED75, and ED90.

induced p53 phosphorylation in $\operatorname{Ser}^{15}$ and $\operatorname{Ser}^{392}$ (data not shown). To test the hypothesis of functional activation of p53 upon exposure to DCA, in parallel experiments we have analyzed the levels of a subset of p53 transcriptional targets involved in promoting cell cycle arrest (p21), modulation of apoptosis (MDM2, Bax, PUMA) or metabolism (TIGAR) by RT-PCR. As shown in Figure $3 \mathrm{~B}, \mathrm{DCA}$ variably but significantly ( $>2$ fold) increased the mRNA levels of MDM2, p21, PUMA and TIGAR in all leukemic cell lines investigated, while no significant modulation of $B A X$ mRNA was observed.

\section{DCA plus Nutlin-3 combination exhibits a potent synergistic anti-leukemic activity}

In the next group of experiments, we have examined the potential interaction of DCA with Nutlin-3, a small molecule which transcriptionally activates p53 by abolishing its interaction with its principal inhibitor MDM2 [20]. For this purpose, leukemic cells were treated with DCA (3-30 mM) and Nutlin-3 (1-10 $\mu \mathrm{M})$, used as single agents and in combination. In particular, B-CLL leukemic cells were treated with serial concentrations of DCA and Nutlin-3 at a constant DCA:Nutlin-3 ratio for data analysis by the method of Chou and Talalay [21]. 
Combined treatment with DCA+Nutlin-3 resulted in significantly $(p<0.01)$ greater cytotoxicity with respect to the single agents, with a synergistic effect both in primary B-CLL patient samples as well as in B leukemic cell lines (Figure 4A-B), as documented by an average Combination Index $(\mathrm{CI})<1$ (Table 2 ). The cytotoxicity induced by the combined treatment with DCA+Nutlin-3 was mainly due to the increase of the degree of apoptosis with respect to the treatment with DCA or Nutlin-3 used alone (Figure 4C).

\section{Role of p21 induction in DCA and DCA+Nutlin-3 induced cytotoxicity in leukemic cells}

With respect to DCA treatment, Nutlin-3 induced a much more potent accumulation of both p53 and its molecular targets MDM2 and p21 in p53 $3^{\text {wild-type leukemic }}$ cells, as documented by Western blot analysis performed on total cell lysates (Figure 5A). The combination of DCA+Nutlin-3 did not result in a further accumulation of p53 protein with respect to Nutlin-3 alone while it promoted a greater induction of MDM2 and p21 proteins with respect to Nutlin-3 alone (Figure 5A). Interestingly, the combination of Nutlin-3+DCA significantly $(\mathrm{p}<0.05)$ enhanced the induction of MDM2 and $p 21$ at the mRNA level, in both B leukemic cell lines and primary B-CLL patient samples, but not in normal PBMC (Figure 5B). Of note, the synergistic transcriptional induction of $\mathrm{p} 53$ target genes by DCA+Nutlin-3, documented in leukemic cells but not in normal PBMC, correlated with the lower cytotoxicity of DCA+Nutlin-3 in these cells (Figure 5C).

Starting from the data illustrated above, which demonstrate that DCA+Nutlin-3 strongly synergized both in promoting leukemic cytotoxicity as well as in inducing p53 transcriptional activity, it was particularly noteworthy that one of the genes up-regulated in response to $\mathrm{DCA} \pm$ Nutlin-3 was $p 21$. In this respect, a recent study has demonstrated that a strong induction of p21 by genotoxic agents was predictive of better prognosis in B-CLL [22]. Conversely, a lack of induction of p21 was observed in B-CLL patient samples showing a worse prognosis even in the presence of an integral activation of p53 [22]. Therefore, in order to functionally elucidate the role of p21 in mediating the anti-leukemic activity of DCA+Nutlin-3, we utilized siRNAs to attenuate p21 expression. The knock-down of p21 expression was demonstrated by quantitative RT-PCR, documenting a significant reduction of p21 mRNA in EHEB cells, transfected with a cocktail of p21 specific siRNAs, both at baseline as well as after DCA+Nutlin-3 treatment (Figure 6A). Of note, in EHEB samples in which p21 expression was knocked-down by transfection with p21 specific siRNAs, the DCA+Nutlin-3-mediated cytotoxicity was significantly $(p<0.05)$ reduced with respect to either cells transfected with a scrambled control siRNA or cells not transfected (Figure 6B). Overall, these experiments support a potential role of p21 in modulating the antileukemic activity of DCA+Nutlin-3.

\section{DISCUSSION}

In this study, we have demonstrated for the first time that DCA exerts cytotoxic activity in primary B-CLL patient samples, but not in normal PBMC obtained from healthy individuals, in the same range of concentrations previously used in studies performed on solid tumors and

\section{A}
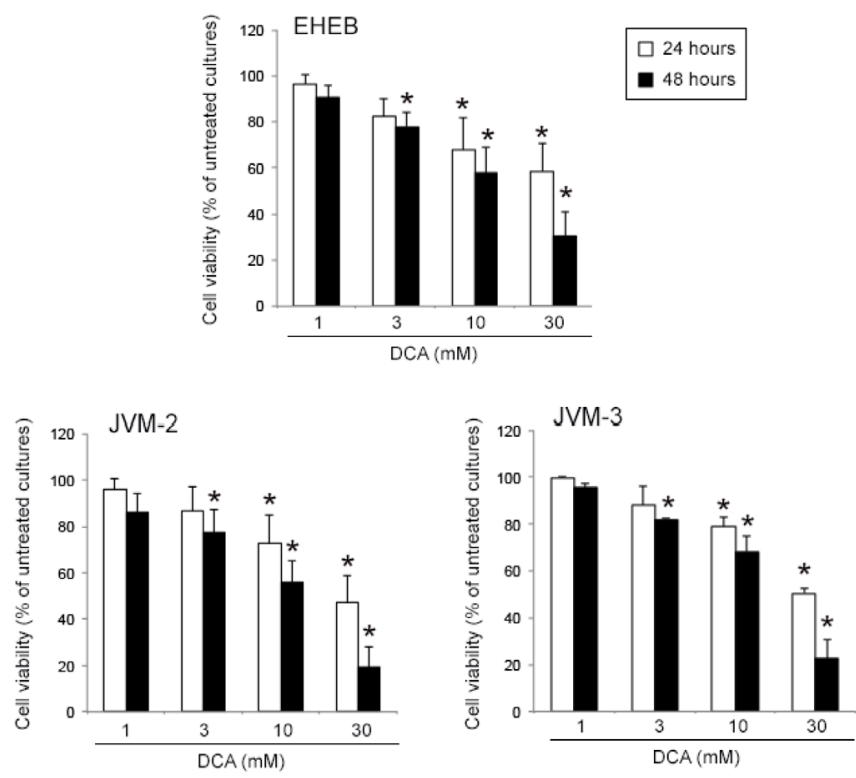

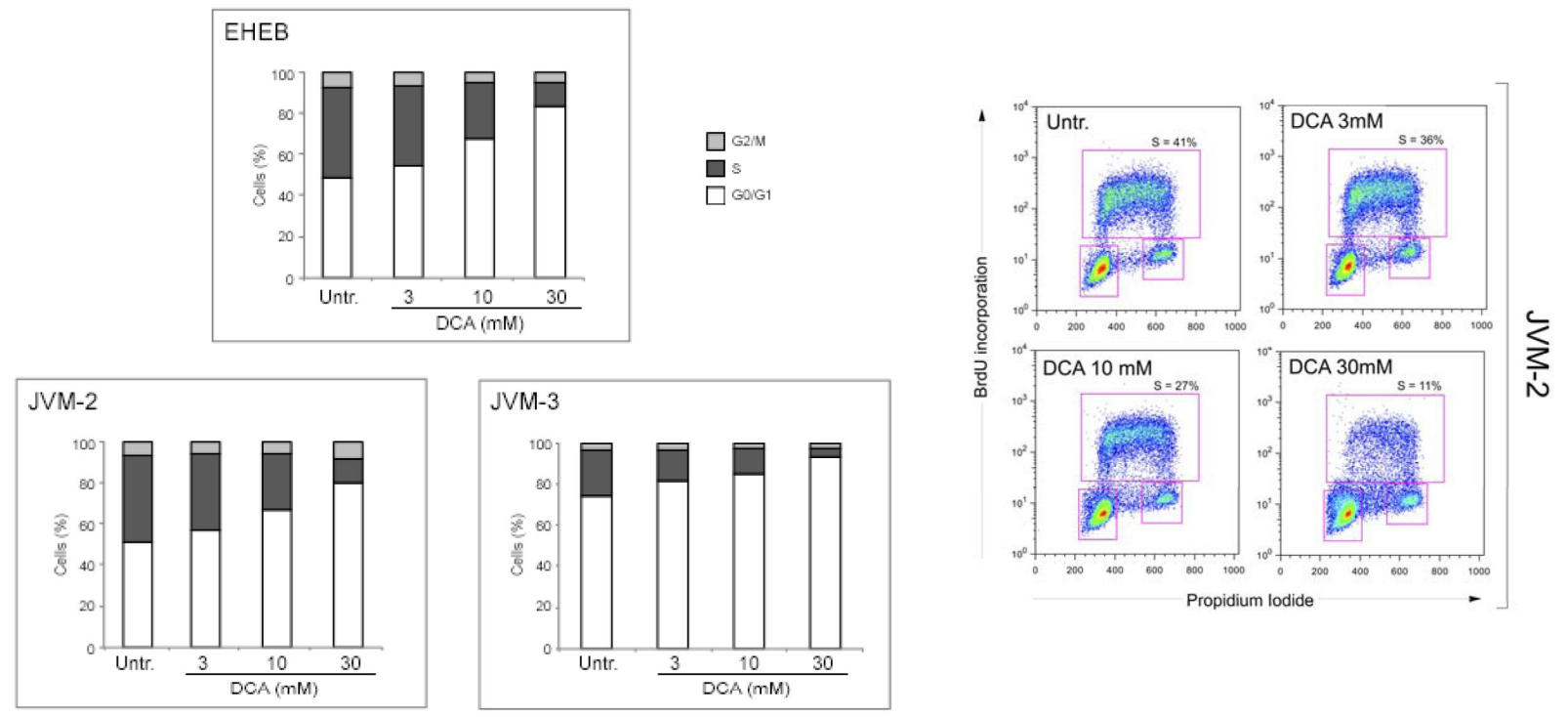

C
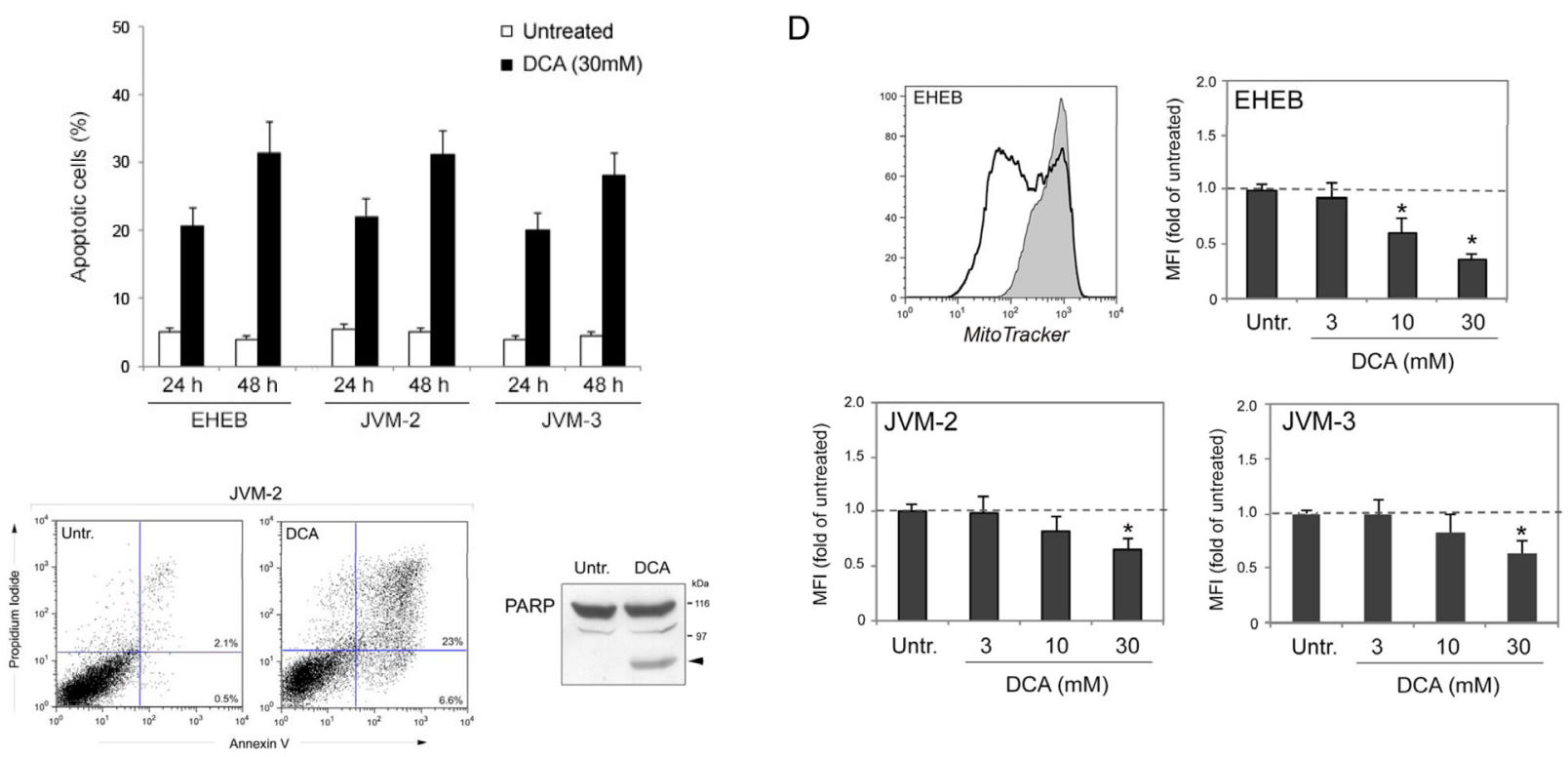

Figure 2: Cytotoxicity induced by DCA in B leukemic cell lines. The p53 $3^{\text {wild-ype }}$ (EHEB, JVM-2, JVM-3) B leukemic cell lines were exposed to DCA before analysis of cell toxicity. In A, cell viability in response to serial doses of DCA (range 1-30 mM), was calculated at both 24 and 48 hours of treatment as percentage with respect to the control vehicle cultures (set to $100 \%$ for each cell line). In $\mathrm{B}$, cell distribution in the different phases of cell cycle was calculated from the flow cytometry dot plots after BrdU/PI staining and expressed as percentage of the total population. Representative cell-cycle profiles of cells, either left untreated or treated with serial doses of DCA, analyzed by flow cytometry are shown. In the right panel, the rectangles represent the cells in G0/G1, S, G2/M phases of the cell cycle. In C, the percentage of apoptotic cells was determined by flow-cytometry after Annexin V/PI staining (upper panel). A representative flow cytometric analysis of apoptosis, validated also by Western blot analysis of PARP cleavage, is shown (lower panels). In D, to measure changes in the mitochondrial membrane potential $\left(\Delta \mathrm{Y}_{\mathrm{m}}\right)$, upon treatment with DCA for $24 \mathrm{~h}$ cells were stained with MitoTracker solution and analyzed by flow cytometry. Median values of mitochondrial MitoTracker fluorescence and representative histograms are shown. In A, $\mathrm{C}$ and $\mathrm{D}$, data are reported as the mean $\pm \mathrm{SD}$ of results from three independent experiments. In $\mathrm{A}$ and $\mathrm{D}$, the asterisk indicates $\mathrm{p}<0.05$ with respect to the untreated cultures of each cell line. 

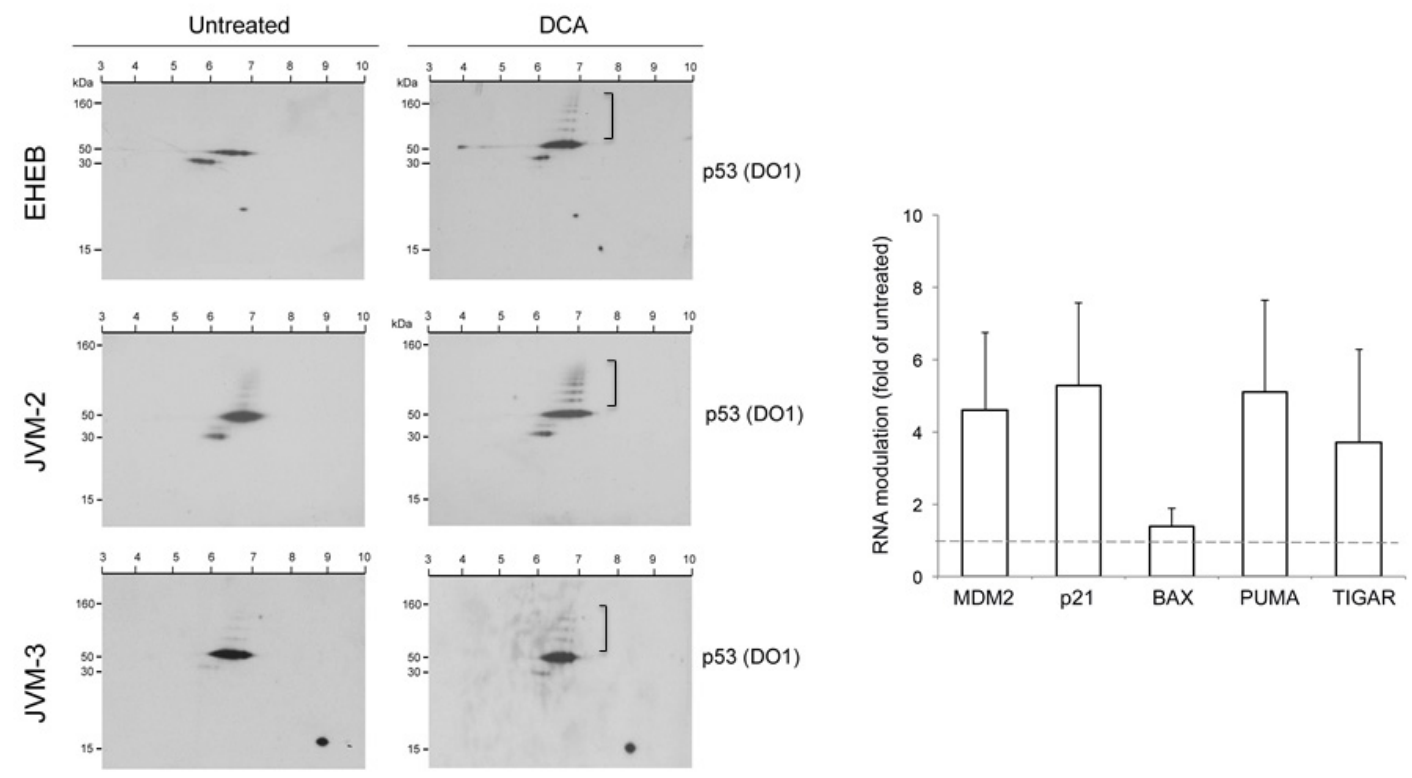

Figure 3: Activation of p53 pathway by DCA in p53 ${ }^{\text {wild-type }}$ B leukemic cells. p53 $3^{\text {wild-type }}$ B leukemic EHEB, JVM-2 and JVM-3 cells were left untreated or treated with DCA for 24 hours. In A, cell lysates were analyzed by two-dimensional immunoblot. The antibody p53 (DO-1) identified a spot group corresponding to full-length p53 ( 53 kDa) and a series of p53 isoforms with a molecular weight above $53 \mathrm{kDa}$ (square brackets). In $\mathrm{B}$, transcriptional activation of p53 target genes, MDM2, p21, BAX, PUMA and TIGAR, was assessed by quantitative RT-PCR. mRNA levels are expressed as folds of modulation, with respect to the control untreated cultures set at 1 . Results are reported as means \pm SD of six independent experiments carried out on the three different cell lines.

A
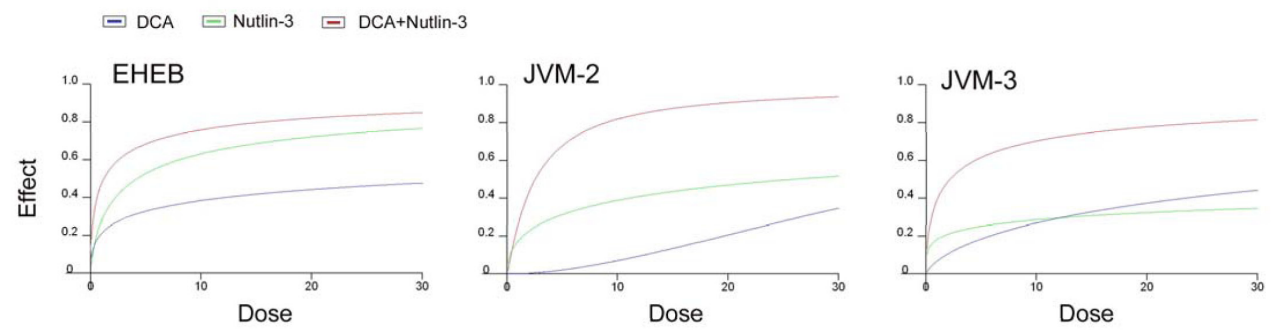

B
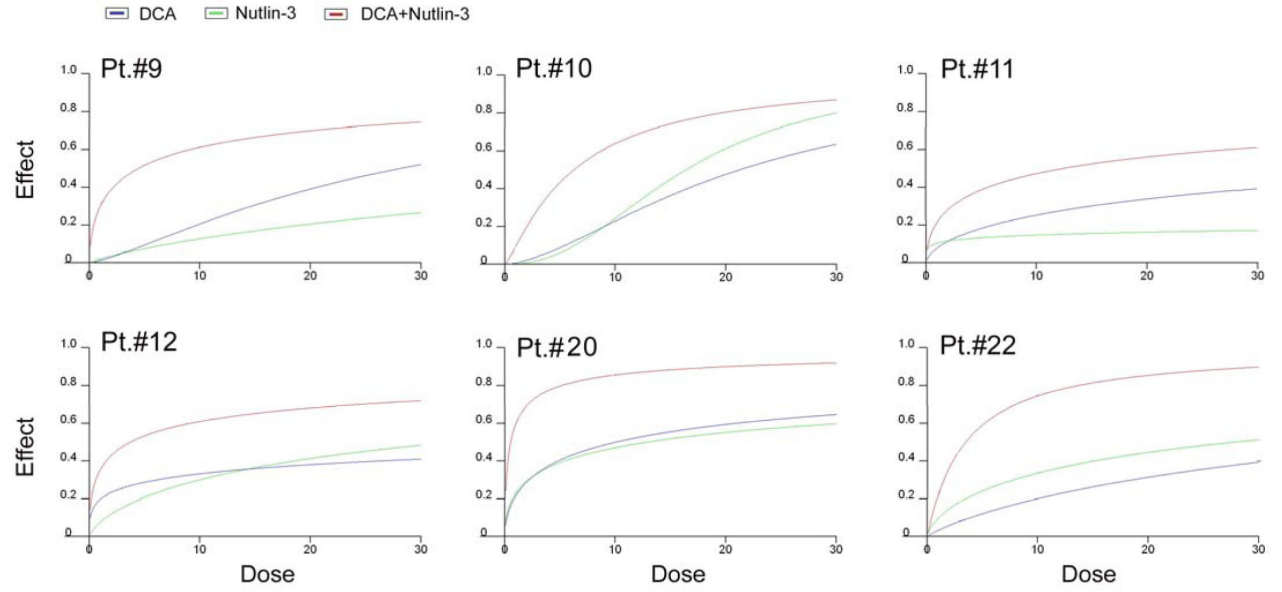


\section{C}
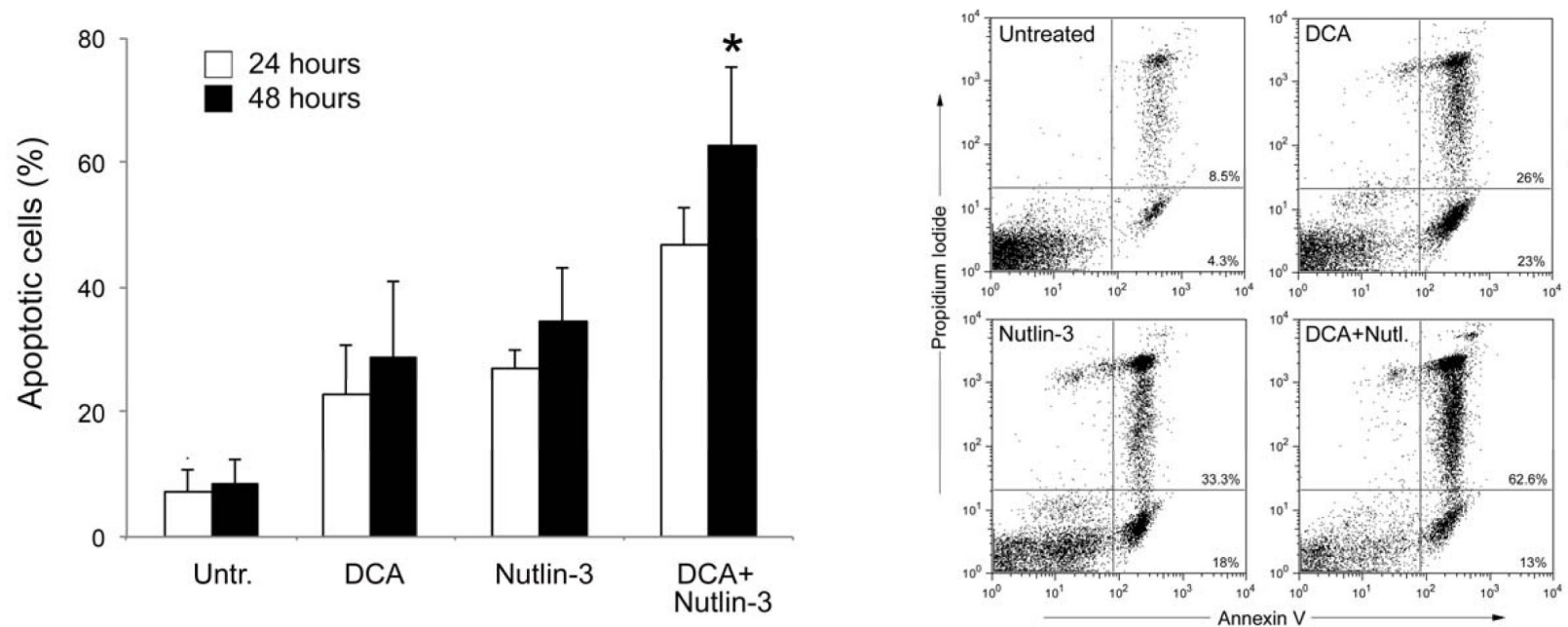

Figure 4: Cytotoxicity by DCA and Nutlin-3 used alone or in combination in p53 ${ }^{\text {wild-type }}$ B leukemic cells and B-CLL patient leukemic cells. p53 $3^{\text {wildtype }}$ B leukemic EHEB, JVM-2 and JVM-3 cells and B-CLL patient leukemic cells were exposed to serial doses of DCA or Nutlin-3 used either alone or in combination, with a fixed ratio, for 24 hours. Dose-effect plots, to determine drug efficacy, are shown for each cell line (A) and for representative B-CLL patient samples (B). The decrease of cell viability, labeled "effect" on the Y-axis, was determined in assays done at least twice in duplicate. In C, induction of apoptosis in B-CLL patient leukemic cells was calculated as percentage of Annexin V/PI cells. Data are reported as mean $\pm \mathrm{SD}$ of results from three independent experiments. A representative flow cytometric analysis of apoptosis in a primary B-CLL sample is shown. The asterisk indicates $\mathrm{p}<0.05$ with respect to cultures treated with either DCA or Nutlin-3 alone.

A
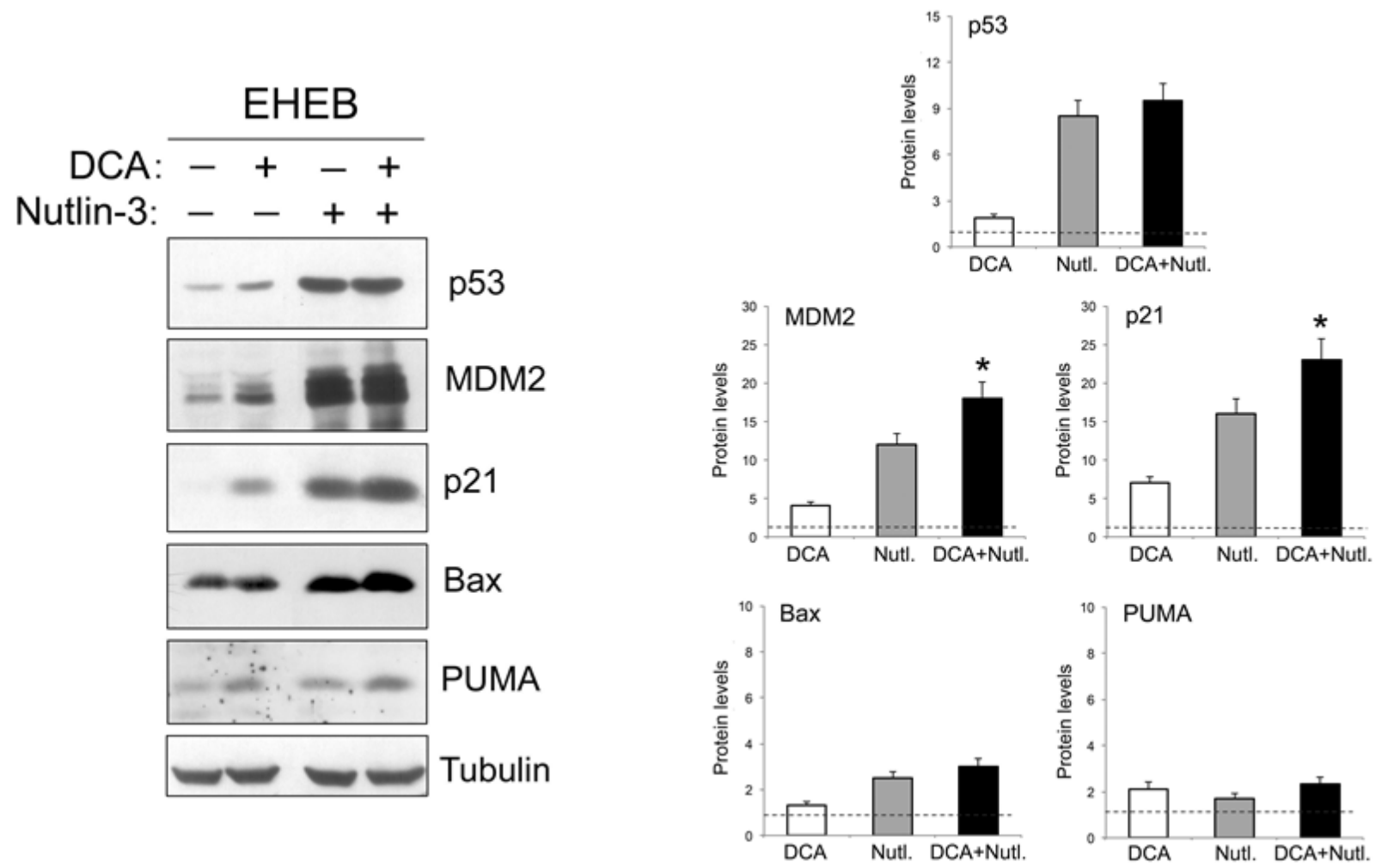

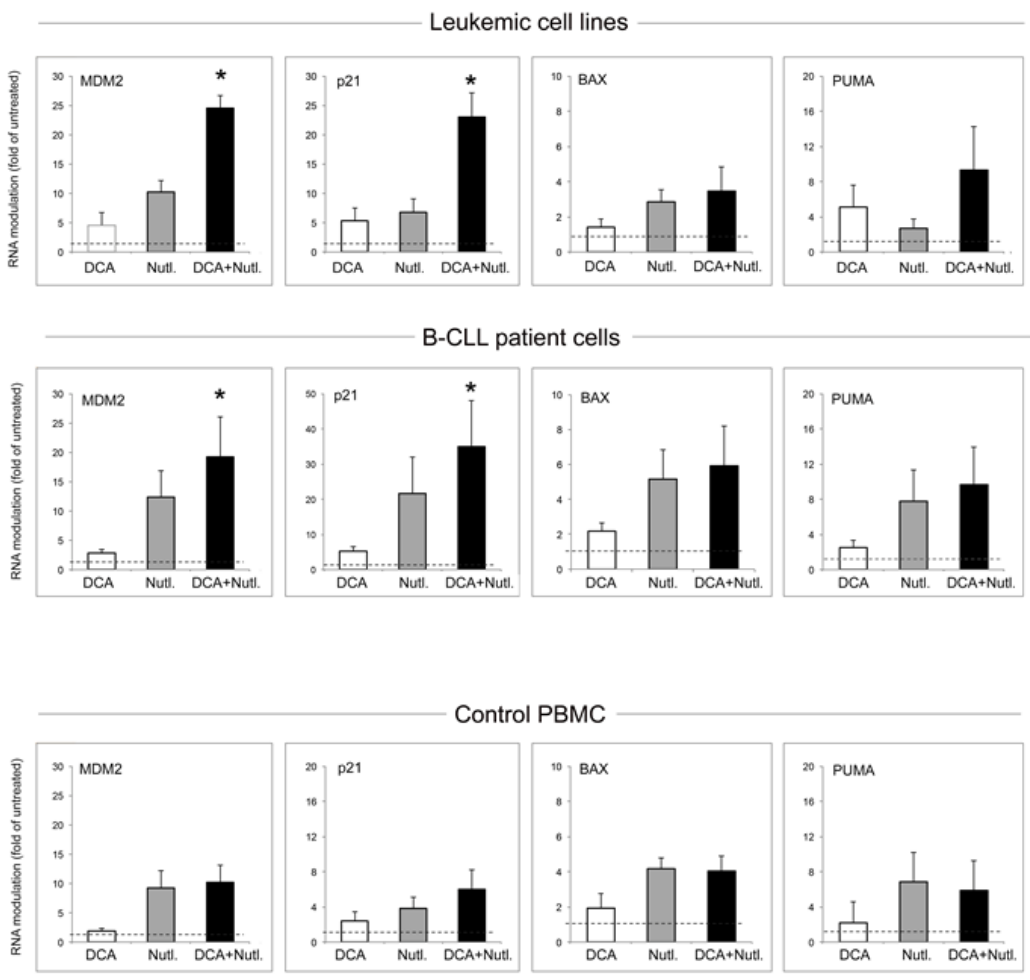

C
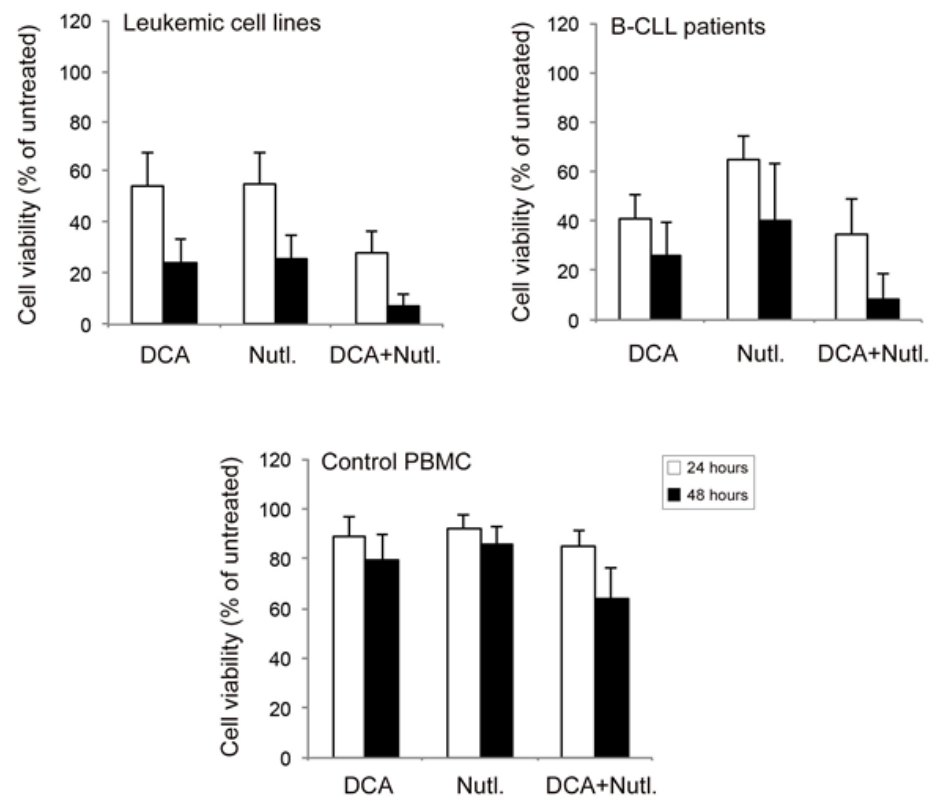

Figure 5: Activation of p53 pathway by DCA+Nutlin-3 combination. In A, equal amounts of cell lysates, obtained from EHEB cells treated for 24 hours with DCA and Nutlin-3, used either alone or in combination, were analyzed for protein levels by Western blot. Tubulin staining is shown as a loading control. Blots representative of at least three independent experiments yielding equivalent results are shown. After densitometric analyses, protein levels are expressed as folds of protein modulation, by the indicated treatments, with respect to the control untreated cultures set at 1. In B and C, p53 $3^{\text {wild-type }} \mathrm{B}$ leukemic cell lines, B-CLL patient leukemic cells and PBMC from healthy human blood donors respectively were exposed for 24 hours to DCA and Nutlin-3, used either alone or in combination, as indicated. In $\mathrm{B}$, the expression levels of 53 target genes were assessed by quantitative RT-PCR and results were indicated as folds of modulation with respect to the control untreated cultures set at 1 . Data are reported as mean $\pm \mathrm{SD}$ of results from independent experiments. The asterisk indicates $p<0.05$ with respect to cultures treated with either DCA or Nutlin-3 alone. In C, cell viability was analyzed at 24 and 48 hours of treatment and was calculated as percentage of untreated cultures set to $100 \%$. Data are reported as mean values \pm SD. 
on multiple myeloma [4-15] and that are therapeutically achievable in vivo. Although the cytotoxic activity of DCA has been attributed to PDK inhibition in solid tumor cell models [1], the concentrations of DCA required to induce apoptosis and/or to inhibit cell proliferation in vitro in $\mathrm{B}$ leukemic cells are several log greater than the inhibition constant (Ki) of PDK. Similar data were previously obtained in studies performed in solid tumors [4-15]. In considering the importance of our current demonstration that DCA shows an anti-leukemic activity, it should be noticed that there are 40 years of human experience with mechanistic studies of DCA in human tissues after oral use, pharmacokinetic and toxicity data from randomized studies [23]. This supports an easy translation to early phase clinical trials. In fact, DCA is an orally bioavailable, low-cost small molecule and currently being evaluated in phase I/II clinical trials for glioblastoma, gliomas and other solid tumors [24]. DCA has interesting characteristics as anticancer drug since it is easily administered and affordable.

By using as a model system a panel of $\mathrm{p} 53^{\text {wild- }}$ type B leukemic cell lines, we demonstrated that DCA induces both cell cycle arrest and apoptosis. Thus, although it has been previously hypothesized that the lack of mitochondrial hyperpolarization in certain types of cancers, including hematological malignancies [25], might render DCA ineffective in such cases, and although the relation between mitochondrial depolarization and cytotoxicity varies in different tumor cell models [26], we found that DCA induced mitochondrial depolarization in B leukemic cell lines. In any case, it should be taken into account that a metabolic heterogeneity has been documented in another model of hematological malignancy, such as multiple myeloma [15] as well as in leukemic cell lines [16].

At the molecular level, DCA induced posttranscriptional modifications of p53 with activation of the p53 transcriptional activity, as documented by

A

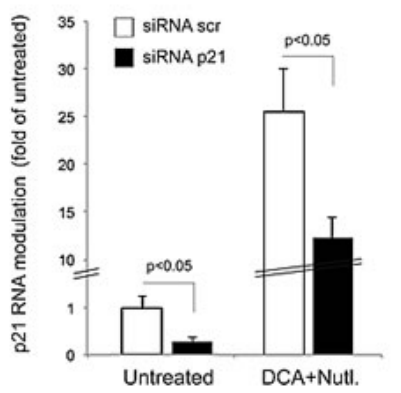

the induction of canonical p53 target genes, such as MDM2, p21 and PUMA but not of BAX. Another major finding of our study was the ability of DCA to potently synergize with Nutlin-3, a non-genotoxic activator of the p53 pathway, in promoting cytotoxicity in B leukemic cell lines as well as in primary B-CLL patient cells, with significantly less toxicity on normal PBMC. The contribution of the transcriptional activity of p53 in promoting leukemic cytotoxicity is still under debate, as transcriptional independent activities have also been demonstrated in previous studies performed with Nutlin-3 $[17,18]$. However, our current data demonstrate the existence of a correlation between the ability to promote the transcription of p53 transcriptional targets, and in particular $p 21$, and the synergistic cytotoxic activity in response to the DCA+Nutlin-3 treatment. Indeed, while the DCA+Nutlin-3 combination was extremely efficient in inducing the transcription of $p 21$ in both primary B-CLL patient samples and B leukemic cell lines, it was significantly less efficient when added to primary normal PBMC. Interestingly, our current demonstration that DCA+Nutlin-3 potently synergized in inducing the transcriptional activation of $p 21$ is noteworthy since the transcriptional induction of $p 21$ has been involved in mediating the therapeutic effect of chemotherapeutic drugs in B-CLL [22]. In this respect, the key role of p21 in mediating the anti-leukemic activity of DCA+Nutlin-3 was confirmed in p21 knock-down experiments. In considering the cytotoxic activity of DCA+Nutlin-3 in p53 $3^{\text {wild-type }} \mathrm{B}-\mathrm{CLL}$ cells, it is noteworthy that rapamycin, like DCA, decreases the Warburg effect by inhibiting the mTOR pathway [27] and that also Nutlin-3 via p53 can inhibit the mTOR pathway [28,29]. Thus, besides inducing $\mathrm{p} 21$, it is possible that inhibition of the mTOR pathway also contributes to the cytotoxicity of the DCA+Nutlin-3 combination.

Since p53 defects are detected in less than $10 \%$ of B-CLL patients at diagnosis $[17,18]$, our study suggests

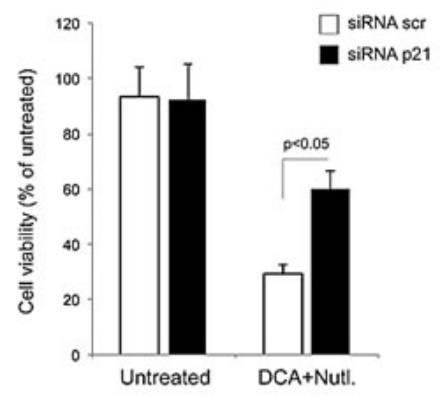

Figure 6: Role of p21 pathway in mediating the anti-leukemic activity of DCA+Nutlin-3. EHEB cells were transfected with either control scrambled (scr) siRNA or p21 siRNA before treatment. In A, after transfection, efficiency of p21 knock-down was documented by analyzing levels of $p 21$ mRNA by quantitative RT-PCR, in untreated cells and upon treatment with DCA+Nutlin-3. Results are expressed as folds of modulation with respect to the control cultures. In B, cultures transfected with either control scrambled (scr) siRNA or p21 siRNA were analyzed for cell viability upon exposure to DCA+Nutlin-3. Results are expressed as percentage with respect to the control vehicle cultures (set to $100 \%$ ). Data are reported as means \pm SD. 
that the anti-leukemic therapeutic potential of DCA, either used alone or in combination with Nutlin-3, is promising and should be further investigated since the majority of B-CLL are suitable to respond to the DCA+Nutlin-3 combination. With respect to the subset of $\mathrm{p} 53^{\text {mutated }} \mathrm{B}-\mathrm{CLL}$ cells, which significantly increases in B-CLL refractory to fludarabine treatment $[17,18]$, it should be explored the possibility that the DCA+Nutlin-3 combination might benefit from the addition of a microtubule active drug, like vinblastine or nocodazole [30-34]. This hypothesis will require further investigations in future studies.

\section{METHODS}

\section{Primary B-CLL patient samples and B leukemic cell lines}

For experiments with primary cells, peripheral blood samples were collected in heparin-coated tubes from 22 B-CLL patients and 10 healthy blood donors following informed consent, in accordance with the Declaration of Helsinki and in agreement with institutional guidelines (University-Hospital of Ferrara). The main clinical parameters of the B-CLL patients were abstracted from clinical records (Table 1). All patients had been without prior therapy at least for three weeks before blood collection.

Peripheral blood mononuclear cells (PBMC) were isolated by gradient centrifugation with lymphocyte cell separation medium (Cedarlane Laboratories, Hornby, ON). T lymphocytes, NK lymphocytes, granulocytes and monocytes were negatively depleted from peripheral blood B-CLL with immunomagnetic microbeads (MACS microbeads, Miltenyi Biotech, Auburn, CA), with a purity $>95 \%$ of resulting $\mathrm{CD} 19^{+}$population, as assessed by flow cytometry analysis and previously described [35]. Primary cells were cultured in RPMI-1640 medium containing 10\% FBS, L-glutamine and penicillin/streptomycin (all from Gibco, Grand Island, NY).

The p53 $3^{\text {wild-type }} \mathrm{B}$ leukemic cell lines EHEB, JVM2, JVM-3 [36] were purchased from DSMZ (Deutsche Sammlung von Mikroorganismen und Zellkulturen $\mathrm{GmbH}$, Braunschweig, Germany) and were routinely cultured in RPMI-1640 supplemented with 10\% FBS, L-glutamine and penicillin/streptomycin (all from Gibco).

\section{Culture treatments, assessment of cell viability, apoptosis, cell cycle profile and glucose consumption}

For in vitro treatments with DCA (Sigma-Aldrich, St Louis, MO), used either alone or in combination with Nutlin-3 (Cayman Chemicals, Ann Arbor, MI), cells were seeded at a density of $1 \times 10^{6}$ cells $/ \mathrm{ml}$ and cultured under normoxic conditions. At different time points after treatment, cell viability was examined by Trypan blue dye exclusion and MTT (3-(4,5-dimethilthiazol2yl)-2,5-diphenyl tetrazolium bromide) colorimetric assay (Roche Diagnostics Corporation, Indianapolis, IN) for data confirmation, as previously described [37]. Levels of apoptosis were quantified by Annexin V-FITC/ propidium iodide (PI) staining (Immunotech, Marseille, France) followed by analysis using a FACSCalibur flow cytometer (Becton-Dickinson, San Jose, CA). To avoid non-specific fluorescence from dead cells, live cells were gated tightly using forward and side scatter, as described $[38,39]$. The cell cycle profile was analyzed by flow cytometry after 5-bromodeoxyuridine (BrdU) incorporation. Briefly, leukemic cells were incubated with $50 \mu \mathrm{M}$ BrdU (Sigma-Aldrich) at $37^{\circ} \mathrm{C}$ for 1 hour. The antibody anti-BrdU (BD Biosciences Pharmingen, San Diego, CA) was bound to BrdU incorporated into neosynthesized DNA and the complex was detected by FITC conjugated secondary antibody (Immunotech). Cells were then stained with PI $(50 \mu \mathrm{g} / \mathrm{mL})$ and analyzed by flow cytometry as previously described [40]. In parallel, glucose consumption was measured as the conversion of glucose to 6-phosphogluconate and NADH with the Glucose (HK) Assay Kit (Sigma-Aldrich), as indicated by the manufacturer and previously described [41].

\section{Flow cytometric assessment of mitochondrial activity}

Mitochondrial activity was evaluated staining cells with MitoTracker ${ }^{\circledR}$ Green ${ }^{\mathrm{FM}}$ (Molecular Probes, Inc., Eugene, Oregon), which passively diffuses across the plasma membrane and accumulates in active mitochondria. Briefly, at different time points, cells were incubated with pre-warmed MitoTracker staining solution (obtained diluting MitoTracker ${ }^{\circledR}$ Green ${ }^{\mathrm{FM}}$ in serum-free medium to a final concentration of $25 \mathrm{nM}$ ) for 30 minutes at $37^{\circ} \mathrm{C}$. Cells were then washed with PBS (Gibco) and analyzed by flow cytometry as previously described [42].

\section{Western blot analyses}

For Western blot analysis, cells were lysed as previously described [43-44]. Protein determination was performed by using the BCA Protein Assay (Thermo Scientific, Rockford, IL). Samples were supplemented with loading buffer (250 mM Tris pH 6.8, 2\% SDS, 10\% glycerin, 4\% beta-mercaptoethanol, 1\% bromophenol blue) and boiled for 2 minutes. Equal amounts of protein for each sample were migrated in SDS-polyacrylamide gels and blotted onto nitrocellulose filters, as previously described $[43,44]$. The following Abs were used: anti-p53 (DO-1), anti-MDM2 (SMP14), anti-p21 (C-19), antiPUMA $\alpha / \beta$ (H-136), anti-PARP-1 (H-250) and anti- 
Bax (2D2) purchased from Santa Cruz Biotechnology (Santa Cruz, CA); anti-Phospho-p53 (Ser15) and antiPhospho-p53 (Ser392) from Cell Signaling Technology (Danvers, MA); anti-tubulin from Sigma-Aldrich. After incubation with anti-mouse or anti-rabbit IgG horseradish peroxidase-conjugated secondary Abs (Sigma-Aldrich), specific reactions were revealed with the ECL Lightning detection kit (Perkin Elmer, Waltham, MA). Densitometry values for Western blot were estimated by the ImageQuant TL software (GE Healthcare, Buckinghamshire, UK) and were expressed as arbitrary units (a.u.). Multiple film exposures were used to verify the linearity of the samples analyzed and to avoid saturation of the film.

\section{Bi-dimensional gel electrophoresis (2-DE) and immunoblotting}

For bi-dimensional gel electrophoresis, protein extraction was performed by adding $150 \mu$ of lysis buffer (5M urea, 2M tiourea, 2\% CHAPS, 2\% Zwittergent detergent; all from Calbiochem, San Diego, CA) with protease inhibitors (Complete, mini EDTA-free mixture, Roche Applied Science, Milan, Italy) to the cell pellets. Lysates were sonicated for $3 \mathrm{~min}$, and 250 units of benzonase endonuclease (Novagen, San Diego, CA) were added to each sample and incubated for 40 minutes at room temperature on rotary shaker. Cell debris were removed by centrifugation at $13000 \mathrm{x}$ f for 10 minutes, $15^{\circ} \mathrm{C}$. The supernatants were aliquoted and stored at $-80^{\circ} \mathrm{C}$. Protein concentration was measured with a modified Bradford method (BioRad, Milan, Italy). Protein extracts $(30 \mu \mathrm{g})$ from each sample were diluted to a final volume of 125 $\mu \mathrm{l}$ in the rehydration solution (5M urea, $2 \mathrm{M}$ thiourea, $2 \%$ CHAPS, 2\% Zwittergent, 100 mM DeStreak, 0.5\% IPG buffer $\mathrm{pH}$ 3-10 linear; all from GE Healthcare) and then applied on immobilized pH 3-10 linear gradient strips, 7 cm (IPG strips, GE Healthcare). Briefly, IPG strips were hydrated on an IPGphor apparatus (GE Healthcare) for 16 $\mathrm{h}$ at $30 \mathrm{~V} / \mathrm{h}$ and then focused for $26 \mathrm{~h}$ until 50,000 V-h. After the first-dimension run, proteins were reduced by LDS Sample Buffer (Life Technologies, Carlsbad, CA) containing $60 \mathrm{mM}$ DTT (GE Healthcare). Proteins were alkylated by $100 \mathrm{mM}$ iodoacetamide (Sigma-Aldrich). The strips were then embedded in $0.7 \%(\mathrm{w} / \mathrm{v})$ agarose on the top of 1-mm-thick acrylamide precast gels at $10 \%$ (Life Technologies). After electrophoresis the proteins were transferred to nitrocellulose membrane by standard electroblotting and stained with MemCode ${ }^{\mathrm{TM}}$ Reversible protein stain kit (Fisher Scientific, Illkirch Cedex, France). After blocking with 5\% dry milk in TBS-Tween 20 for $1 \mathrm{~h}$ at room temperature, the membranes were probed with an anti-p53 (DO-1) antibody (Santa Cruz Biotechnology) and then exposed to the peroxidase-linked specie specific antimouse IgG (Sigma-Aldrich). The p53 positive proteins were visualized using chemiluminescence plus (ECL plus)
Western blotting detection reagents (GE Healtcare).

\section{RNA analyses}

Total RNA was extracted from cells using the QIAGEN RNeasy Plus mini kit (QIAGEN, Hilden, Germany) according to the supplier's instructions. Once verified the quality of RNA preparation by agarose gel, total RNA was transcribed into cDNA, using the QuantiTect $^{\circledR}$ Reverse Transcription kit (QIAGEN). p21, MDM2, BAX, PUMA, TIGAR gene expression was analyzed using the SYBR Green-based real-time quantitative polymerase chain reaction (RT qPCR) detection method with SABiosciences RT $^{2}$ Real- Time ${ }^{\mathrm{TM}}$ Gene expression assays, which include specific validated primer sets and PCR master mix (SABiosciences, QIAGEN). All samples were run in triplicate using the real time thermal analyzer Rotor-Gene ${ }^{\mathrm{TM}} 6000$ (Corbett, Cambridge, UK), as previously described $[45,46]$. Expression values were normalized to the housekeeping gene POLR2A amplified in the same sample.

\section{Transfection experiments}

Leukemic cells $\left(2 \times 10^{6}\right.$ cells $\left./ 0.1 \mathrm{ml}\right)$ were mixed with either $1 \mu \mathrm{g}$ of control enhanced green fluorescence protein (EGFP) plasmid or $2 \mu \mathrm{g}$ of small interfering RNA (siRNA) cocktails, transferred to a $2.0-\mathrm{mm}$ electroporation cuvette and nucleofected with the nucleofector kit V (Lonza Cologne AG, Cologne, Germany) using the nucleofector device (Amaxa Nucleofector II apparatus, Lonza). After electroporation, cells were immediately transferred to a complete medium and cultured at $37^{\circ} \mathrm{C}$ until analysis. Transfection efficiency was monitored in each experiment by scoring the percentage of EGFP-positive cells by flow cytometry analysis. For specific p21 gene knock-down, siRNAs were designed and manufactured by Ambion $^{\circledR}$ (Life Technologies) according to the current guidelines for effective gene knock-down by this method. Negative control siRNA consisted of a $19 \mathrm{bp}$-scrambled sequence with 3' dT overhangs (Ambion's Silencer negative control siRNA). The Ambion's Silencer negative control siRNA sequence has no significant homology to any known gene sequences from human and it has been previously tested for the lack of non-specific effects on gene expression.

\section{Statistical analysis and assessment of the effect of combination treatment}

The results were evaluated by using analysis of variance with subsequent comparisons by Student's t-test and with the Mann-Whitney rank-sum test. Statistical significance was defined as $p<0.05$. In order to investigate the effect of DCA+Nutlin-3 combination, leukemic cells 
were then treated with serial doses of DCA (range 3-30 $\mathrm{mM}$ ) or Nutlin-3 (range 1-10 microM), individually or in combination using a constant ratio (DCA:Nutlin-3). Results were analyzed with the method of Chou and Talalay to determine whether combined treatment yields greater effects than expected from summation alone: a combination index (CI) of 1 indicates an additive effect, while a CI below 1 indicates synergism. For this purpose cell viability data were analyzed with the CalcuSyn software (Biosoft, Cambridge, UK) and reported either as CI values or as dose-effect curves directly drawn by the CalcuSyn software.

\section{ACKNOWLEDGEMENTS}

This study was supported by grants from MIURFIRB (RBAP11Z4Z9_002 to G.Z.; RBAP10447J_002 to P.S.), and from the Italian Association for Cancer Research (AIRC IG 11465 to G.Z.). C.A. has been supported by a "Consorzio Spinner PhD Program".

\section{REFERENCES}

1. Michelakis ED, Webster L, Mackey JR. Dichloroacetate (DCA) as a potential metabolic-targeting therapy for cancer. Br J Cancer. 2008; 99: 989-94.

2. Kim JW, Dang CV. Cancer's molecular sweet tooth and the Warburg effect. Cancer Res. 2006; 66: 8927-30.

3. Chen Y, Cairns R, Papandreou I, Koong A, Denko NC. Oxygen consumption can regulate the growth of tumors, a new perspective on the Warburg effect. PLoS One. 2009; 4: $1-9$.

4. Bonnet S, Archer SL, Allalunis-Turner J, Haromy A, Beaulieu C, Thompson R, Lee CT, Lopaschuk GD, Puttagunta L, Bonnet S, Harry G, Hashimoto K, Porter CJ, Andrade MA, Thebaud B, Michelakis ED. A mitochondria- $\mathrm{K}+$ channel axis is suppressed in cancer and its normalization promotes apoptosis and inhibits cancer growth. Cancer Cell. 2007; 11: 37-51.

5. Michelakis ED, Sutendra G, Dromparis P, Webster L, Haromy A, Niven E, Maguire C, Gammer TL, Mackey JR, Fulton D, Abdulkarim B, McMurtry MS, Petruk KC. Metabolic modulation of glioblastoma with dichloroacetate. Sci Transl Med. 2010; 2: 31ra34.

6. Wong JY, Huggins GS, Debidda M, Munshi NC, De Vivo I. Dichloroacetate induces apoptosis in endometrial cancer cells. Gynecol Oncol. 2008; 109: 394-402.

7. Cao W, Yacoub S, Shiverick KT, Namiki K, Sakai Y, Porvasnik S, Urbanek C, Rosser CJ. Dichloroacetate (DCA) sensitizes both wild-type and over expressing Bcl-2 prostate cancer cells in vitro to radiation. Prostate. 2008; 68: 1223 31.

8. Babu E, Ramachandran S, CoothanKandaswamy V, Elangovan S, Prasad PD, Ganapathy V, Thangaraju M. Role of SLC5A8, a plasma membrane transporter and a tumor suppressor, in the antitumor activity of dichloroacetate. Oncogene. 2011; 30: 4026-37.

9. Sun RC, Fadia M, Dahlstrom JE, Parish CR, Board PG, Blackburn AC. Reversal of the glycolytic phenotype by dichloroacetate inhibits metastatic breast cancer cell growth in vitro and in vivo. Breast Cancer Res Treat. 2010; 120: 253-60.

10. Sun RC, Board PG, Blackburn AC. Targeting metabolism with arsenic trioxide and dichloroacetate in breast cancer cells. Mol Cancer. 2011; 10: 142.

11. Sanchez-Arago M, Chamorro M, Cuezva JM. Selection of cancer cells with repressed mitochondria triggers colon cancer progression. Carcinogenesis. 2010; 31: 567-76.

12. Tong J, Xie G, He J, Li J, Pan F, Liang H. Synergistic antitumor effect of dichloroacetate in combination with 5-fluorouracil in colorectal cancer. J Biomed Biotechnol. 2011; 2011: 740564.

13. Ayyanathan K, Kesaraju S, Dawson-Scully K, Weissbach $\mathrm{H}$. Combination of sulindac and dichloroacetate kills cancer cells via oxidative damage. PLoS One. 2012; 7: e39949.

14. Ishiguro $T$, Ishiguro $M$, Ishiguro $R$, Iwai. Cotreatment with dichloroacetate and omeprazole exhibits a synergistic antiproliferative effect on malignant tumors. Oncol Lett. 2012; 3: 726-8.

15. Sanchez WY, McGee SL, Connor T, Mottram B, Wilkinson A, Whitehead JP, Vuckovic S, Catley L. Dichloroacetate inhibits aerobic glycolysis in multiple myeloma cells and increases sensitivity to bortezomib. Br J Cancer. 2013; 108: 1624-33.

16. Suganuma K, Miwa H, Imai N, Shikami M, Gotou M, Goto M, Mizuno S, Takahashi M, Yamamoto H, Hiramatsu A, Wakabayashi M, Watarai M, Hanamura I, Imamura A, Mihara H, Nitta M. Energy metabolism of leukemia cells: glycolysis versus oxidative phosphorylation. Leuk Lymph. 2010; 51: 2112-9.

17. Secchiero P, di Iasio MG, Gonelli A, Zauli G. The MDM2 inhibitors Nutlins as an innovative therapeutic tool for the treatment of hematological malignancies. Curr Pharm Des. 2008; 14: 2100-10.

18. Secchiero P, Zauli G. TNF-related apoptosis-inducing ligand and the regulation of hematopoiesis. Curr Op in Hematol. 2008; 15: 42-48.

19. Kumar A, Kant S, Singh SM. Novel molecular mechanisms of antitumor action of dichloroacetate against $\mathrm{T}$ cell lymphoma: Implication of altered glucose metabolism, $\mathrm{pH}$ homeostasis and cell survival regulation. Chem Biol Interact. 2012; 199: 29-37.

20. Secchiero P, Bosco R, Celeghini C, Zauli G. Recent advances in the therapeutic perspectives in nutlin-3. Curr Pharm Des. 2011; 17: 569-77.

21. Chou T, Talalay P. Quantitative analysis of dose-effect relationships: the combined effects of multiple drugs or enzyme inhibitors. Adv Enzyme Regul. 1984; 22: 27-55.

22. Lin K, Adamson J, Johson GG, Carter A, Oates M, Wade R, 
Richards S, Gonzalez D, Matutes E, Dearden C, Oscier DG, Catovsky D, Pettitt AR. Functional analysis of the ATMp53-p21 pathway in the LRF CLL4 trial: blockade at the level of p21 is associated with short response duration. Clin Cancer Res. 2012; 18: 4191-200.

23. Kerr DS. Review of clinical trials for mitochondrial disorders: 1997-2012. Neurotherapeutics. 2013; 10: 307-19.

24. Yeluri S, Madhok BM, Jayne DG. New horizons in cancer therapy: manipulating tumour metabolism. Biomed Res. 2010; 23: 17-23.

25. Chen LB. Mitochondrial membrane potential in living cells. Annu Rev Cell Biol. 1988; 4: 155-81.

26. Stockwin LH, Yu SX, Borgel S, Hancock C, Wolfe TL, Phillips LR, Hollingshead MG, Newton DL. Sodium Dichloroacetate (DCA) selectively targets cells with defects in the mitochondrial ETC. Int J Cancer. 2010; 127: 2510-9.

27. Leontieva OV, Blagosklonny MV. M(o)TOR of pseudohypoxic state in aging: rapamycin to the rescue. Cell Cycle. 2014; 13: 509-15.

28. Demidenko ZN, Korotchkina LG, Gudkov AV, Blagosklonny MV. Paradoxical suppression of cellular senescence by p53. Proc Natl Acad Sci USA. 2010; 107: 9660-4.

29. Levine AJ, Harris CR, Puzio-Cuter AM. The interfaces between signal transduction pathways: IGF-1/mTor, p53 and the Parkinson disease pathway. Oncotarget. 2012; 3: 1301-7.

30. Blagosklonny MV. The power of chemotherapeutic engineering: arresting cell cycle and suppressing senescence to protect from mitotic inhibitors. Cell Cycle. 2011; 10: 2295-8.

31. van Leeuwen IM, Rao B, Sachweh MC, Lain S. An evaluation of small-molecule p53 activators as chemoprotectants ameliorating adverse effects of anticancer drugs in normal cells. Cell Cycle. 2012; 11: 1851-61.

32. Apontes P, Leontieva OV, Demidenko ZN, Li F, Blagosklonny MV. Exploring long-term protection of normal human fibroblasts and epithelial cells from chemotherapy in cell culture. Oncotarget. 2011; 2: 222-33.

33. Rao B, van Leeuwen IM, Higgins M, Campbel J, Thompson AM, Lane DP, Lain S. Evaluation of an actinomycin D/ VX-680 aurora kinase inhibitor combination in p53-based cyclotherapy. Oncotarget 2010. 1: 639-50.

34. van Leeuwen IM. Cyclotherapy: opening a therapeutic window in cancer treatment. Oncotarget 2012. 3: 596-600.

35. Secchiero P, Melloni E, di Iasio MG, Tiribelli M, Rimondi E, Corallini F, Gattei V, Zauli G. Nutlin-3 up-regulates the expression of Notch1 in both myeloid and lymphoid leukemic cells, as part of a negative feedback antiapoptotic mechanism. Blood. 2009; 113: 4300-8.

36. Melo JV, Foroni L, Brito-Babapulle V, Luzzatto L, Catovsky D. The establishment of cell lines from chronic B cell leukaemias: evidence of leukaemic origin by karyotypic abnormalities and Ig gene rearrangement. Clin
Exp Immunol. 1988; 73: 23-8.

37. Re MC, Zauli G, Gibellini D, Furlini G, Ramazzotti E, Monari P, Ranieri S, Capitani S, La Placa M. Uninfected haematopoietic progenitor $(\mathrm{CD} 34+)$ cells purified from the bone marrow of AIDS patients are committed to apoptotic cell death in culture. AIDS. 1993; 7: 1049-55.

38. Vitale M, Zamai L, Falcieri E, Zauli G, Gobbi P, Santi S, Cinti C, Weber G. IMP dehydrogenase inhibitor, tiazofurin, induces apoptosis in K562 human erythroleukemia cells. Cytom Part B-Clin Cytom. 1997; 30: 61-6.

39. Zauli G, La Placa M, Vignoli M, Re MC, Gibellini D, Furlini G, Milani D, Marchisio M, Mazzoni M, Capitani S. An autocrine loop of HIV type-1 Tat protein responsible for the improved survival/proliferation capacity of permanently tat-transfected cells and required for optimal HIV-1 LTR transactivating activity. J Acquir Immune Defic Syndr Hum Retrovirol. 1995; 10: 306-16.

40. Zauli G, Voltan R, Bosco R, Melloni E, Marmiroli S, Rigolin GM, Cuneo A, Secchiero P. Dasatinib plus Nutlin-3 shows synergistic antileukemic activity in both p53 wildtype and $\mathrm{p} 53$ mutated $\mathrm{B}$ chronic lymphocytic leukemias by inhibiting the Akt pathway. Clin Cancer Res. 2011; 17: 76270.

41. Hulleman E, Kazemier KM, Holleman A, VanderWeele DJ, Rudin CM, Broekhuis MJ, Evans WE, Pieters R, Den Boer ML. Inhibition of glycolysis modulates prednisolone resistance in acute lymphoblastic leukemia cells. Blood. 2009; 113: 2014-21.

42. Martinez-Outschoorn UE, Lin Z, Trimmer C, Flomenberg N, Wang C, Pavlides S, Pestell RG, Howell A, Sotgia F, Lisanti MP. Cancer cells metabolically "fertilize" the tumor microenvironment with hydrogen peroxide, driving the Warburg effect: implications for PET imaging of human tumors. Cell Cycle. 2011; 10: 2504-20

43. Gibellini D, Bassini A, Pierpaoli S, Bertolaso L, Milani D, Capitani S, La Placa M Zauli G. Extracellular HIV-1 Tat protein induces the rapid Ser133 phosphorylation and activation of CREB transcription factor in both Jurkat lymphoblastoid $\mathrm{T}$ cells and primary peripheral blood mononuclear cells. J Immunol. 1998; 160: 3891-8.

44. Secchiero P, Sun D, De Vico AL, Crowley RW, Reitz MS Jr, Zauli G, Lusso P, Gallo RC. Role of the extracellular domain of human herpesvirus 7 glycoprotein $\mathrm{B}$ in virus binding to cell surface heparan sulfate proteoglycans. J Virol. 1997; 71: 4571-80.

45. Zauli G, Voltan R, di Iasio MG, Bosco R, Lelloni E, Sana ME, Secchiero P. miR-34a induces the down-regulation of both E2F1 and B-Myb oncogenes in leukemic cells. Clin Cancer Res. 2011; 17: 2712-24.

46. Zauli G, Celeghini C, Melloni E, Voltan R, Ongari M, Tiribelli M, di Iasio MG, Lanza F, Secchiero P. The Sorafenib plus Nutlin-3 combination promotes synergistic cytotoxicity in acute myeloid leukemic cells irrespectively of the FLT3 and p53 status. Haematologica. 2012; 97: 1722-30. 